\title{
Pérdida de acreditación institucional y sus efectos sobre la retención de primer año: Universidad de Las Américas 2010-2014, Chile
}

\author{
Cristóbal A. Castro*, Constanza A. Pavez y Francisco J. Contreras \\ Universidad de Las Américas, Av. Manuel Montt 948, Providencia, Santiago-Chile \\ (Correo-e: cristobal.castro@udla.cl; cpavezm@udla.cl; francisco.contreras@udla.cl) \\ * Autor a quien debe ser dirigida la correspondencia.
}

Recibido Ene. 21, 2021; Aceptado Mar. 23, 2021; Versión final May. 31, 2021, Publicado Oct. 2021

\begin{abstract}
Resumen
El objetivo del presente estudio es determinar cuánto del impacto que la pérdida de acreditación (2013) tiene sobre la tasa de retención de primer año de la Universidad de Las Américas (Chile) se debe a un empeoramiento de las condiciones de financiamiento y cuánto al deterioro en la percepción de la calidad de la institución. Utilizando datos administrativos de esta institución entre 2010 y 2014, se aplicó una técnica de análisis econométrico de descomposición no lineal para modelos discretos. Los resultados muestran que la caída en la tasa de retención se debe principalmente a la pérdida del acceso a financiamiento mediante crédito con aval del estado, aunque los cambios en la percepción explican hasta un tercio de esta caída. Comparando las cohortes 2013 y 2014, se concluye que el efecto de las percepciones sobre la institución es mayor en el año que se pierde la acreditación.
\end{abstract}

Palabras clave: acreditación; educación superior; retención; financiación

\section{Loss of institutional accreditation and its effects on first-year retention: Universidad de Las Américas 2010-2014, Chile}

\begin{abstract}
The primary objective of the present study is to determine how much of the impact that the loss of accreditation (2013) has on first-year retention rate at the Universidad de Las Américas (Chile) is due to a worsening of financing conditions and how much is due to degradation of the perception about the institution's quality. Using administrative data from the Universidad de Las Américas between the years 2010 and 2014, a non-linear decomposition econometric analysis technique for discrete models is applied. The results show that retention rate drop is mainly due to the loss of access to governmental financing credits, although changes in perception explain up to a third of retention rate drop. By comparing the 2013 and 2014 cohorts, it is concluded that perceptions most affect the educational institution in the year (2013) that accreditation is lost.
\end{abstract}

Keywords: accreditation; higher education; retention; funding 


\section{INTRODUCCIÓN}

El crecimiento tanto de la matrícula como de la cobertura constituyen dos de los fenómenos más característicos de la educación superior chilena en las últimas décadas. Entre 1990 y 2015, la cantidad de estudiantes en educación superior se incrementó de 249.408 a 1.165.654, lo que significó pasar de una cobertura de 15,6\% en 1990 a 53,1\% en 2015 (Espinoza, 2017). Esta expansión de la matrícula es consistente en gran medida al ingreso de actores privados en el sistema a partir de la Reforma de 1981, así como posteriormente a una creciente disponibilidad de financiamiento estudiantil (becas y créditos), fundamentalmente desde los 90 (Rau et al., 2013). Así, al efecto del Fondo Solidario de Crédito Universitario, que reemplaza en 1994 al Crédito Universitario, se sumó en 2005 el Crédito con Garantía Estatal (CAE).

Esta rápida expansión de la matrícula y la cobertura hizo posible el acceso a la educación universitaria de sectores antes excluidos, dando lugar a una diversificación del perfil de los estudiantes (Espinoza 2017). Dichas transformaciones han planteado importantes desafíos al sistema educativo, especialmente en cuanto a la retención de este nuevo grupo de estudiantes (Navarrete et al., 2013). La retención, entendida como "la persistencia de los estudiantes en un programa de estudios universitarios hasta lograr su grado o título" (Himmel, 2002), no solo es relevante por su relación con la calidad de la docencia y el aprendizaje (AranedaGuirriman et al., 2013), sino que también se vincula a la eficiencia de recursos en distintos niveles. Por una parte, mayores niveles de retención suponen una disminución en la cantidad de recursos económicos que los estudiantes y sus familias necesitan para completar sus estudios. Por otra, una mayor retención ayuda a mejorar la eficiencia de las políticas de acompañamiento tanto de las universidades como del Estado (SIES, 2014a). Asimismo, la retención conlleva una mejora en factores psicosociales de los estudiantes, como frustraciones y expectativas no cumplidas (SIES, 2014b).

En este contexto, la tasa de retención de primer año ha recibido particular atención, ya que la mayor parte de la deserción ocurre en ese periodo. En Chile, aproximadamente tres de cada diez estudiantes dejan su carrera durante el primer año (Santelices et al., 2016). Aunque abundan los trabajos acerca de la retención y deserción en el sistema terciario, se ha prestado menos atención al impacto que tienen variables de carácter institucional sobre la retención. Una de estas variables, que tiene particular relevancia, es la acreditación institucional. La acreditación institucional es un proceso que busca evaluar el cumplimiento del proyecto corporativo de las entidades de educación superior, así como verificar que dispongan de mecanismos eficaces de autorregulación y de aseguramiento de la calidad (Barra, 2019). La acreditación tiene importantes consecuencias para estas instituciones y especialmente para las universidades. Estas consecuencias son fundamentalmente de dos tipos: 1) En Chile, el financiamiento desde el Estado está condicionado al proceso de acreditación, tal que los estudiantes pueden optar a créditos y becas del Estado sólo para cursar estudios en instituciones acreditadas. A su vez, contar con financiamiento debiera traducirse en una menor deserción por motivos financieros (Himmel, 2002). Por otra parte, los estudiantes que se integran a una institución que pierde la acreditación no pueden postular a financiamiento estatal, mientras que los estudiantes antiguos pierden la posibilidad de postular a financiamiento del que no sean beneficiarios de antemano; y 2) La pérdida de acreditación tendría un fuerte impacto negativo en la imagen institucional, vale decir, en la percepción del público y de los propios estudiantes respecto de la calidad de la formación impartida en una institución determinada (Mulyono et al. 2020).

El presente trabajo busca abordar la relación entre retención universitaria y acreditación a partir del caso de la Universidad de Las Américas (UDLA), institución que perdió su acreditación en el año 2013. Así, el objetivo del estudio es determinar cuánto de la caída en la tasa de retención de primer año de la UDLA en 2014 se debe a un empeoramiento de las condiciones de financiamiento y cuánto al deterioro en la percepción de calidad que los estudiantes tienen de la institución. Para esto comparamos las cohortes de estudiantes que ingresaron a la UDLA entre 2010 y 2012, cuando la universidad estaba acreditada, con las cohortes correspondientes a 2013 -que pasaron por el proceso de pérdida de acreditación-y 2014 -que ingresaron a la institución sabiendo que no estaba acreditada. Para ello, se usó la metodología econométrica de descomposición no lineal para modelos discretos propuesta por Yun (2004), que permite identificar el peso específico de cambios en las variables observables como el tipo de financiamiento (efecto característica), y de cambios que ponderan dichas variables observables (efecto parámetro), que sería atribuible al cambio de percepción de los estudiantes asociado al cambio de estatus de acreditación de la institución.

\section{OTROS ANTECEDENTES}

Para contextualizar el presente trabajo se detallan, a continuación, una serie de antecedentes adicionales relativos al desarrollo del sistema de educación superior chileno, el proceso de acreditación institucional y el caso de la UDLA. Posteriormente se presentan los principales modelos teóricos mediante los que se entiende la retención/deserción y una revisión de la investigación sobre la retención/deserción en Chile. 


\section{El sistema de educación superior chileno y la acreditación institucional}

Hasta 1980, el sistema de educación superior en Chile se componía de ocho universidades, dos de las cuales pertenecían al Estado y concentraban el $65 \%$ de la matrícula. Aunque las seis restantes eran privadas, más de dos tercios de los ingresos del sector universitario era asumido por el sector público (Espinoza, 2017). La combinación de una baja cobertura de la educación media, una matrícula limitada y la selectividad daba lugar a un sistema elitista y cerrado. La reforma educacional de 1981 posibilitó la creación de universidades privadas autofinanciadas, institutos profesionales (IP) y centros de formación técnica (CFT), diversificando el sistema. A su vez, la nueva legislación desagregó las dos grandes universidades estatales existentes, tal que muchas de las antiguas sedes pasaron a ser universidades regionales (Espinoza, 2017).

Otro cambio fundamental fue la introducción un nuevo modelo de financiamiento: una parte considerable de los costos fueron transferidos desde el Estado a los estudiantes y sus familias mediante el cobro de matrículas y aranceles que se extiende tanto a entidades públicas como privadas (Espinoza, 2017). Al mismo tiempo, se creó un sistema de becas y créditos estatales dirigido a estudiantes vulnerables de las universidades existentes antes de 1981, las que se agruparon en el Consejo de Rectores de Chile (CRUCH). La diversificación institucional y la transformación de los sistemas de financiamiento introducidos en 1981 tienen un gran impacto en la matrícula, de manera que en 2015 solo un $27 \%$ de los estudiantes estaban matriculados en universidades del $\mathrm{CRUCH}$, mientras que el $73 \%$ restante estaba matriculado en universidades privadas (31\%) o en IPs y CFTs (42\%) (Espinoza, 2017).

Hasta el año 2013 el Estado subsidiaba el pago de aranceles por medio de programas condicionados al cumplimiento de diferentes criterios. El $52 \%$ de la matrícula recibe algún tipo de beneficio estudiantil (SIES, 2014b). En ese momento, además de un conjunto de becas de arancel, existían dos tipos de crédito estudiantil: el Fondo Solidario de Crédito Universitario (cuyo acceso está restringido a estudiantes de universidades acreditadas y que pertenezcan al grupo de universidades que existían al 31 de diciembre de 1980, sumado a las estatales creadas a partir de 2015) y el Crédito con Aval del Estado (CAE), dirigido a estudiantes de instituciones de educación superior autónomas, acreditadas institucionalmente y adscritas al Sistema de Crédito para Estudios Superiores.

La reforma de 1981 - al permitir la entrada de actores privados-, dio paso a una gran diversificación institucional y al aumento significativo de la matrícula y cobertura del nivel terciario. Actualmente, existen 18 universidades estatales, 9 particulares con aporte fiscal directo del Estado y 29 privadas, muchas de las cuales reciben población antes excluida del sistema. Sin embargo, este proceso de diversificación y crecimiento del sistema de educación superior se dio en un marco de profunda desregulación institucional, dando lugar a retos en materia de calidad, factor que resulta clave en el contexto de una amplia oferta institucional (Espinoza, 2017). Con el fin de regular la calidad de las instituciones, se consolida en 2006 el Sistema Nacional de Aseguramiento de la Calidad de la Educación Superior (Mineduc, 2006). Asimismo, las iniciativas de acreditación para instituciones y programas iniciadas experimentalmente por la Comisión Nacional de Acreditación de Pregrado (CNAP) y la Comisión Nacional de Acreditación de Posgrado (CONAP), se formalizan con la creación de la Comisión Nacional de Acreditación (CNA) en 2007 y la autorización de Agencias Privadas de Acreditación.

La acreditación de instituciones tiene como finalidad evaluar el cumplimiento del proyecto institucional de las entidades, así como verificar que dispongan de mecanismos eficaces de autorregulación y de aseguramiento de la calidad. En este contexto, la calidad es evaluada en función de los propósitos declarados de las carreras e instituciones, así como los criterios establecidos por las respectivas comunidades académicas y profesionales (Barra, 2019). Estos procesos son voluntarios y están abiertos solo para las instituciones reconocidas como autónomas por el Consejo Nacional de Educación (CNED). Los resultados de la acreditación institucional se expresan como una decisión binaria: acreditada o no acreditada, con gradaciones de uno a siete años de vigencia. En 2015 , el $100 \%$ de las universidades estatales y privadas $\mathrm{CRUCH}$ se encontraba acreditada, mientras que en las privadas esta cifra llegaba al 63\% (Huerta-Riveros y Gaete-Feres, 2018). Una consecuencia de la acreditación institucional refiere a la opinión de la ciudadanía acerca de las instituciones de educación superior, ya que se plantea como garantía pública de calidad. Particularmente en el caso de las universidades privadas, la acreditación genera una suerte de homologación o mejora competitiva (Mulyono et al., 2020) respecto a las universidades tradicionales.

\section{El caso de la UDLA}

La UDLA desarrolló su primer proceso de acreditación institucional en 2007 con resultados negativos. Luego de apelar ante el CNED, éste revirtió el dictamen, otorgándole a la universidad una acreditación de dos años en las áreas obligatorias de gestión institucional y docencia de pregrado. En 2010 se sometió de nuevo al proceso y logró la acreditación por tres años. Un tercer proceso ocurrió en 2013. La CNA no acreditó la 
institución, decisión que fue confirmada por el CNED en enero de 2014. En la actualidad, está acreditada por cuatro años (hasta marzo del 2023), estando vigente la decisión de la CNA desde el 17 de marzo de 2019 en las áreas obligatorias de Gestión Institucional y Docencia de Pregrado. La pérdida de la acreditación tuvo un impacto negativo en la universidad, especialmente en la matrícula de estudiantes potenciales beneficiarios del CAE (UDLA, 2015). Asimismo, tuvo un efecto sobre los estudiantes de cursos superiores, muchos de los cuales abandonaron la institución. Al comparar la admisión 2015 (universidad no acreditada) versus la del 2013 (universidad acreditada), se observa una caída de 51\% en la matrícula de estudiantes de primer año y de $11 \%$ para el caso de los estudiantes de cursos superiores que debían rematricularse (UDLA, 2015). Este artículo busca determinar cuánto de la variación significativa en la tasa de retención global de primer año producto de la pérdida de acreditación institucional, se debió a las menores posibilidades de financiamiento y cuánto al daño en la imagen institucional.

El de la UDLA es un caso de estudio relevante por distintas razones. En primer lugar, es el primer caso de una institución de educación superior que, estando acreditada, pierde esa condición. En ese momento (2013) era la segunda universidad más grande del sistema en matrícula de pregrado, concentrando el $5 \%$ de la matrícula total de todo el país (SIES, 2014b). Finalmente, la UDLA puede considerarse una institución paradigmática, en la medida que por su sistema de acceso y composición de matrícula refleja la realidad de un gran segmento del sistema universitario chileno. En este sentido, constituye un caso de interés para instituciones similares que, de no establecer mecanismos permanentes de mejoramiento de sus procesos académicos y administrativos, entre otros aspectos, ponen en riesgo la acreditación institucional.

\section{Principales modelos de retención/deserción}

Himmel (2002) define la retención como la persistencia de los estudiantes en un programa de estudios universitarios hasta lograr su grado o título. La deserción, por otro lado, alude al abandono prematuro de un programa de estudios, previo a la obtención de su grado o título y considera un tiempo lo suficientemente largo como para descartar la posibilidad de que el estudiante se reincorpore. De acuerdo a Himmel (2002), existen dos tipos de deserción: voluntaria e involuntaria. La primera corresponde a la renuncia o al abandono informado, por parte del estudiante, a la institución de educación superior La deserción involuntaria, por otra parte, es consecuencia de una decisión institucional ajustada a reglamentos internos que obliga al estudiante a dejar los estudios. El presente estudio aborda el primero de estos tipos: la deserción voluntaria.

Tanto la deserción voluntaria como su inverso, la retención, son fenómenos multicausales y, por consiguiente, han sido estudiados desde diferentes perspectivas. Braxton et al. (1997) agrupan los estudios sobre retención y deserción de acuerdo con el énfasis que le otorgan a distintos tipos de variables explicativas, identificando cinco grandes enfoques: psicológicos, sociológicos, económicos, organizacionales y de interacciones. Los enfoques psicológicos centran su atención en variables individuales, vale decir, en características y atributos de los estudiantes que puedan dar cuenta de la deserción o persistencia en el sistema.

Dentro de este tipo de enfoque, destaca el modelo de Fishbein y Ajzen (1975), quienes, asumiendo que el comportamiento está influido significativamente por creencias y actitudes, plantean que la decisión de desertar o continuar en un programa académico se debería a conductas previas, a actitudes sobre la deserción y/o la persistencia y a normas subjetivas que generan una intención conductual, que se traduce en un comportamiento definido. Attinasi Jr. (1989) agrega a este modelo que la persistencia y la deserción se ven influidas por las percepciones de los estudiantes y el análisis que éstos hacen de su vida universitaria después de su ingreso. Ethington (1990), sobre la base de los modelos anteriores, incorpora elementos de la teoría de conductas de logro de Eccles et al. (1983), estableciendo que el rendimiento académico previo influye significativamente en el desempeño futuro del estudiante. La influencia del rendimiento académico estaría dada por el efecto que tiene sobre el autoconcepto del estudiante, su percepción de la dificultad de los estudios y sus metas, valores y expectativas de éxito.

Los enfoques sociológicos, por su parte, enfatizan la influencia en la retención de factores externos al individuo. Al respecto, Spady (1970) propone que la deserción es el resultado de la falta de integración de los estudiantes a la educación superior y señala que el medio familiar es una de las principales fuentes que los exponen a influencias, expectativas y demandas, afectando su nivel de integración social en la universidad. Por otra parte, los enfoques económicos asumen la perspectiva del análisis de costos y beneficios, planteando que los estudiantes permanecen en la educación superior en la medida en que los beneficios que obtienen por ser estudiantes - sociales y/o económicos - sean mayores que sus costos. Así, lo central en este caso es la decisión de un estudiante de desertar o no de sus estudios superiores, basado en una comparación entre los costos y beneficios asociados a tales alternativas (Santelices et al., 2016). Estos enfoques incluyen gran parte de los estudios que examinan los programas de rebajas de matrícula, crédito y becas (St. John et al., 2000). 
Por otra parte, los modelos organizacionales abordan la deserción desde las características de las instituciones universitarias, particularmente en relación con los servicios y prestaciones que ofrecen (Braxton et al., 2000). A su vez, los enfoques de interacción explican la deserción a partir de las relaciones tanto formales como informales que se generan entre los estudiantes y las instituciones (Braxton et al., 1997). Las relaciones formales son aquellas establecidas específicamente con sus pares y docentes en el ámbito académico, mientras que las informales refieren a las actividades extracurriculares.

A estas categorías debe agregarse el enfoque integrado —entre los cuales se enmarca esta investigación-, que recoge aportes de las perspectivas anteriores (St. John et al., 2000) De acuerdo a este enfoque, si un estudiante está integrado social y académicamente en una institución -es decir, si establece buenas relaciones y tiene un buen desempeño académico- existe una mayor probabilidad de que se mantenga en ésta. En línea con los enfoques económicos, plantea que los estudiantes actuarían con un criterio costobeneficio en la construcción de su integración social y académica, evitando conductas asociadas a costos y buscando relaciones, interacciones y estados emocionales que involucren recompensas. A su vez, si los beneficios de permanecer en la institución son percibidos por los estudiantes como mayores que los costos personales involucrados -tales como esfuerzo y dedicación-, seguirán en ella. Por el contrario, si los estudiantes perciben otras actividades como fuentes de mayores recompensas, tenderán a desertar (Tinto, 1975). Pese a estas similitudes, mientras que los enfoques económicos priorizan el impacto de variables como los beneficios económicos de los estudiantes, los enfoques de integración se centran en la integración social y académica de los estudiantes. El modelo de Tinto (1975) considera, además, que, en el tránsito de los estudiantes por la educación superior, las variables que contribuirían a reforzar su adaptación a la institución tienen un carácter diverso.

El presente trabajo entiende la deserción desde un enfoque integrado, considerando principalmente dos tipos de variables que afectarían la integración de los estudiantes al perder la condición de acreditación de UDLA. Por una parte, en base al enfoque económico, la pérdida de la acreditación, al imposibilitar a estudiantes nuevos la obtención del CAE -entre otras formas de financiamiento estatal-, produciría un alza el costo de mantenerse e ingresar a la institución. A su vez, este desbalance en la relación costo-beneficio afectaría negativamente la integración de los estudiantes en la institución, aumentando su probabilidad de desertar.

Por otra parte, como señalan los enfoques psicológicos, las creencias y actitudes en los estudiantes son centrales para su integración. Investigaciones desarrolladas con estudiantes universitarios en España (Beerli Palacio et al., 2002), India (Thomas, 2011), 8 países en oriente medio (Azoury et al., 2014) y Tailandia (Kunanusorn y Puttawong, 2015) dan cuenta de dos componentes del factor subjetivo: el componente cognitivo y el componente afectivo. El primero refiere al conocimiento y las creencias que los estudiantes tienen sobre la institución -incluyendo la reputación de ésta-y es el punto de partida de la relación de fidelidad de los estudiantes. El componente afectivo refiere a los sentimientos de compromiso con sus estudios y la institución. Mientras el primero se relaciona fundamentalmente con la imagen corporativa de la institución, el segundo se desarrolla durante la vida universitaria. Así, el factor cognitivo precede al afectivo, aunque ambos contribuyen a la satisfacción y, por lo tanto, a la permanencia.

\section{Antecedentes sobre retención/deserción en Chile}

En Chile, los datos oficiales sobre la matrícula de las instituciones de educación superior son recolectados y procesados por el Servicio de información de Educación Superior (SIES), organismo que dispone de las bases de datos de la matrícula para primer año desde 2011. Operacionalmente, la tasa de retención corresponde al cociente entre el número de estudiantes que se mantienen en una carrera o programa de una institución determinada y el total de los estudiantes que ingresaron a dicha carrera o programa como estudiantes de primer año. (Mineduc, 2012). En Chile, la tasa de retención aumentó entre 2014 y 2018, pasando de un 71\% a un $75 \%$. Para la cohorte correspondiente a 2018 , las instituciones acreditadas presentan una mayor tasa de retención de primer año (76,5\%), mientras que las instituciones sin acreditación alcanzaron un 57,6\% (SIES, 2019b).

En el caso de la UDLA, la tasa de retención de primer año en 2014 fue de 61,9\%, vale decir, prácticamente 15 puntos porcentuales menos respecto de la misma tasa registrada para el resto de las universidades. Por otra parte, se observa una fuerte variación de este indicador cuando se comparan las cohortes de ingreso estando la institución acreditada y sin acreditación. La tasa de retención promedio de primer año con la universidad acreditada (cohortes 2010, 2011 y 2012) fue de 78\%, mientras que sin acreditación (cohortes 2013 y 2014) bajó a 65\% (UDLA, 2015).

A partir de los datos del SIES se observa que ciertas características de los estudiantes se asocian con mayores tasas de retención de primer año en todo el sistema universitario (SIES, 2019b). Una de estas características - vinculada con el nivel socioeconómico- es el establecimiento educacional de origen, tal 
que los matriculados que provienen de establecimientos particulares pagados tienen mayores tasas de retención (79\% en promedio en el periodo 2014-2018) que aquellos de establecimientos particulares subvencionados $(74,6 \%)$ y municipales $(70,8 \%)$ (SIES, $2019 \mathrm{~b})$. Por otra parte, los datos muestran una clara relación entre el puntaje de la Prueba de Selección Universitaria (PSU) y la retención. En 2012, quienes presentaban puntajes mayores o iguales a 800 puntos -siendo el puntaje máximo 850-, tenían una tasa de retención de primer año superior al 95\%. Por el contrario, para quienes presentaban puntajes menores a 450 puntos, este indicador era de 56,8\% (SIES, 2014a). Dado esto, es posible afirmar que las universidades de baja selectividad -que acogen en mayor medida a estudiantes provenientes de colegios particulares subvencionados, municipales y con bajos puntajes PSU— tienen una mayor probabilidad de presentar tasas de retención de primer año más bajas que aquellas más selectivas.

Otro factor asociado a la tasa de retención es el acceso a financiamiento mediante ayudas estudiantiles, que incluyen las becas de arancel del Ministerio de Educación, el Fondo Solidario de Crédito Universitario y el CAE. En 2012 existía una diferencia de 20 puntos porcentuales entre la tasa de retención de estudiantes con ayudas estudiantiles estatales (80,3\%) y la de estudiantes sin beneficios de este tipo (58,1\%). En el caso de las universidades privadas, se observa que aquellas que reciben estudiantes con una combinación de becas y CAE, tienen tasas de retención de primer año más altas $(86,5 \%)$, mientras que aquellas que solo reciben a estudiantes con CAE muestran una tasa de retención mayor que las que reciben únicamente becados (SIES, 2014a). En la UDLA se presentan diferencias importantes en cuanto a las tasas de retención de primer año entre estudiantes con y sin CAE. Entre 2010-2012 (acreditada), la tasa de retención promedio de los estudiantes con CAE fue de $86 \%$, mientras que la de los estudiantes sin CAE fue de $72 \%$. Esta diferencia se mantiene en 2013 y 2014 (sin acreditación), incluso con la caída general de la retención, de manera que las tasas de retención de primer año de estudiantes con y sin este beneficio son de $75 \%$ y $62 \%$, respectivamente (UDLA, 2015).

En términos de la investigación académica, los estudios sobre retención en la educación superior en Chile han abordado los efectos de distintas variables, aunque la mayor parte de éstos se centra en el efecto que tienen los créditos sobre la retención (Santelices et al., 2016). Rau et al. (2013), por ejemplo, abordan la relación entre el CAE y la deserción y concluyen que este tipo de beneficio reduce la probabilidad de deserción en primer año en un 6,8\% en el caso de los estudiantes matriculados en carreras de cinco años y un 64,3\% para los matriculados en instituciones de dos o cuatro años. Este efecto es mayor en el caso de los estudiantes más vulnerables.

Por otra parte, de acuerdo a Santelices et al. (2016), existen factores socioeconómicos (grupos de menores ingresos, con padres con menor educación) y académicos (peores puntajes PSU y Notas de Enseñanza Media-NEM) que influyen en el aumento en la deserción. Las autoras utilizan un modelo de deserción para las universidades chilenas que incluyó variables demográficas, socioeconómicas, académicas e institucionales, además del acceso a beneficios estudiantiles. Además de los factores socioeconómicos y académicos, el estudio identifica el efecto de las variables género -las mujeres tienen un mayor nivel de retención-y acreditación -las instituciones acreditadas tienen mayores niveles de retención. No obstante, su principal conclusión que existe una relación positiva entre los beneficios estudiantiles y la retención, vínculo que es más fuerte en el caso de los estudiantes de menores ingresos, especialmente en el caso del CAE. En otra investigación, el Centro de Estudios del Ministerio de Educación (Mineduc, 2012), demuestra que los factores más relevantes para la permanencia de los estudiantes son la acreditación de la institución, la vocación (definida por el número de preferencia del estudiante al elegir su carrera) y las ayudas estudiantiles (becas y créditos).

Estos antecedentes muestran que, aunque la investigación sobre la retención en Chile es extensa, la mayor parte de la literatura vincula la retención con atributos individuales de los estudiantes (demográficos, económicos, académicos, etc.). En este sentido, faltan estudios que relacionen la retención a atributos institucionales, como la acreditación. Incluso cuando se aborda la relación entre retención y acreditación, esto se hace mediante la comparación entre universidades acreditadas y no acreditadas, no considerando los efectos que, a lo largo del tiempo, tienen los cambios en esta condición, vale decir, la pérdida de acreditación institucional. Por otra parte, la literatura no profundiza en la dimensión subjetiva del efecto que tiene la acreditación institucional sobre la retención. Considerando lo anterior, el presente estudio busca cubrir este vacío, analizando, a partir del caso de la UDLA, el impacto de la pérdida de acreditación tanto en el perfil de los estudiantes y su acceso a beneficios estudiantiles como en la imagen institucional.

\section{METODOLOGÍA}

La metodología empleada en este trabajo es de orden cuantitativo. La información en la que se basa proviene de registros administrativos y se encuentra contenida en bases de datos de la UDLA correspondientes a estudiantes de primer año del periodo en que la universidad se encontraba acreditada (años 2010, 2011 y 
2012), del año en que perdió la acreditación (2013) y del año siguiente (2014). Estos datos son ingresados año a año para las nuevas cohortes de estudiantes por la Dirección de Análisis Institucional, que colecta información académica como el NEM, la PSU, el colegio de origen de los estudiantes y el programa en que se matriculan (diferenciando entre carreras técnicas y profesionales, así como entre régimen y facultad); variables sociodemográficas como la edad y el sexo; e información financiera, como si recibe el CAE. Al ser datos administrativos, la información utilizada es de carácter censal, incluyendo la información de todos los estudiantes nuevos por cohorte. Cabe destacar que la información utilizada es anónima y no es para uso del público general. Su uso en este estudio cuenta con la autorización de la UDLA.

Con el fin de darle continuidad y significación estadística al análisis, se consideran programas académicos que hayan estado vigentes por los últimos cinco años y que cuenten con más de cinco estudiantes. A su vez, para que la muestra se componga de estudiantes que al menos cursaron un semestre, se restringe la muestra para aquellos alumnos que tienen notas superiores a 1,5 (siendo 7,0 la nota máxima), ya que a los estudiantes que no cumplen con este requisito se asignan notas 1,0 . Con estas consideraciones se generaron tres grupos de comparación: El primer grupo está constituido por las cohortes que ingresaron entre 2010 y 2012, periodo en que la universidad se encontraba acreditada. El segundo grupo corresponde a la cohorte de ingreso 2013, año en que la UDLA pierde su acreditación. El tercer grupo se compone de la cohorte de ingreso 2014, momento en que la universidad lleva a cabo su primer proceso de admisión habiendo perdido su condición de acreditada. Así, el grupo 1 (2010-2012) cuenta con 24.018 estudiantes, el grupo 2 (2013) cuenta con 10.492 estudiantes y el grupo 3 (2014) cuenta con 5.774 estudiantes.

Estos tres grupos se establecen con la finalidad de hacer dos análisis: Por una parte, se busca comparar la retención de la UDLA en un periodo en el que cuenta con acreditación (Grupo 1) con el momento en el que pierde su estado de acreditada (Grupo 2), es decir, un momento en el que se modifican las condiciones bajo las cuales los estudiantes ingresaron a la universidad. Por otra parte, se busca comparar el periodo de acreditación institucional (Grupo 1) con un momento en que los estudiantes ingresan a la UDLA sabiendo que no estaba acreditada, es decir, en el que no hay cambios en las condiciones de ingreso (Grupo 3). Esto es relevante en la medida que -como se profundizará en las hipótesis- el cambio en las condiciones de ingreso de los estudiantes sería determinante del tipo de variable que explica las variaciones en la tasa de retención.

El análisis se llevó a cabo mediante una descomposición no lineal para modelos discretos, propuesta por Yun (2004). Esta técnica corresponde a una expansión del modelo de Blinder (1973) y Oaxaca (1973), construido para variables dependientes dicotómicas. Una descomposición no lineal es una forma de separar diferentes variables independientes que afectan de manera no lineal a una variable dependiente que, a su vez, no se comporta linealmente, es decir, una variable dependiente que no puede graficarse con una línea. Al considerar la retención de primer año como una variable dependiente dicotómica (donde 1 implica retención y 0 significa abandono), la metodología de Yun (2004) permite responder la pregunta acerca de cuánto de la brecha en la tasa de retención entre dos grupos de comparación puede ser explicada por un "efecto característica" cambios en los niveles de un número determinado de variables independientes las variables explicativas o perfil de los estudiantes, como el financiamiento a través del CAE- y cuánto por un "efecto parámetro" -un ponderador del comportamiento de las variables independientes incluidas en el modelo.

Las variables independientes consideradas son el NEM, la PSU, el porcentaje de alumnos que rinde la PSU por cohorte, la edad, el sexo, el colegio de origen, el régimen de estudios, el nivel de carrera, la facultad y si posee el CAE en diferentes periodos de tiempo. Estas variables fueron escogidas en tanto son reconocidas en la literatura por mediar la integración de los estudiantes en las instituciones de educación superior y, por lo tanto, su decisión de mantenerse en éstas o desertar.

La aplicación de la metodología de Yun (2004) a nuestro estudio se puede resumir en las siguientes cuatro ecuaciones:

$$
\begin{aligned}
& \bar{R}_{t}-\bar{R}_{t^{\star}}=\sum_{i=1}^{k} \mu_{\Delta x}^{i}\left[\overline{F\left(X_{t} \beta_{t}\right)}-\overline{F\left(X_{t^{*}} \beta_{t}\right)}\right]+\sum_{i=1}^{k} \mu_{\Delta \beta}^{i}\left[\overline{F\left(X_{t^{*}} \beta_{t}\right)}-\overline{F\left(X_{t^{*}} \beta_{t^{\star}}\right)}\right] \\
& \mu_{\Delta x}^{i}=\frac{\left(\bar{X}_{t}^{i}-\bar{X}_{t^{*}}^{i}\right) \beta_{t}^{i} f\left(\bar{X}_{t} \beta_{t}\right)}{\left(\bar{X}_{t}-\bar{X}_{t^{*}}\right) \beta_{t} f\left(\bar{X}_{t} \beta_{t}\right)}=\frac{\left(\bar{X}_{t}^{i}-\bar{X}_{t^{*}}^{i}\right) \beta_{t}^{i}}{\left(\bar{X}_{t}-\bar{X}_{t^{*}}\right) \beta_{t}} \\
& \mu_{\Delta \beta}^{i}=\frac{\bar{X}_{t^{*}}^{i}\left(\beta_{t}^{i}-\beta_{t^{\star}}^{i}\right) f\left(\bar{X}_{t^{\star}} \beta_{t^{\star}}\right)}{\bar{X}_{t^{*}}\left(\beta_{t}-\beta_{t^{\star}}\right) f\left(\bar{X}_{t^{\star}} \beta_{t^{*}}\right)}=\frac{\bar{X}_{t^{*}}^{i}\left(\beta_{t}^{i}-\beta_{t^{*}}^{i}\right)}{\bar{X}_{t^{*}}\left(\beta_{t}-\beta_{t^{*}}\right)}
\end{aligned}
$$


con:

$$
\sum_{i=1}^{k} \mu_{\Delta x}^{i}=\sum_{i=1}^{k} \mu_{\Delta \beta}^{i}=1
$$

En estas ecuaciones, $\mathrm{R}$ es la variable dependiente, es decir, la tasa de retención de primer año, $t$ y t* son dos momentos de tiempo diferentes, $\mathrm{F}$ es una función de distribución acumulada de una normal estandarizada y $\beta$ los parámetros que miden la sensibilidad de la tasa de retención respecto a variaciones de las variables independientes (explicativas) X. La principal ecuación es la (1), que muestra la descomposición que tiene cada efecto (característica y parámetro) sobre la tasa de retención. El primer término del lado derecho corresponde al efecto del cambio en las características de la muestra (cambios en X), mientras que el segundo término muestra el efecto de un cambio en las percepciones de los estudiantes (cambios en $\beta$ ). Las barras superiores indican el promedio de la variable correspondiente, mientras que $\mu_{\Delta x}$ y $\mu_{\Delta \beta}$ son el peso o la ponderación de cambios en las variables explicativas y en los parámetros de sensibilidad, respectivamente.

Como se señaló anteriormente, la descomposición permite conocer si las variaciones en la retención de primer año se deben a cambios en las características observables propias de cada estudiante, que entenderemos como "efecto característica" (el efecto producto de variaciones en las variables explicativas X) y/o a cambios estructurales de la institución, que entenderemos como "efecto parámetro" (que corresponde al efecto de variaciones en los parámetros $\beta$ que miden la sensibilidad de la tasa de retención ante cambios de X). Específicamente, aquí interesa determinar en qué porcentaje la baja en la tasa de retención promedio de primer año puede ser explicada por cambios en las variables independientes y qué porcentaje por cambios en los parámetros $\beta$.

Cabe destacar que desagregar los cambios de la tasa de retención en efecto característica y efecto parámetro permite identificar el efecto de la pérdida de acreditación sobre la tasa de retención. Como se señaló en los antecedentes, la literatura sobre retención releva, por una parte, un conjunto de variables individuales (puntaje psu, sexo, etc.) y, por otra, la acreditación como los factores más importantes que se asocian a la retención. En la medida que el conjunto de variables individuales son incluidas en el modelo estadístico como parte del efecto característica y que no se observan otros cambios institucionales, es posible identificar el efecto parámetro con el efecto de la acreditación. Este último, a su vez, supone dos tipos de efecto: sobre el financiamiento -especialmente sobre el acceso al CAE-y sobre la imagen institucional. Puesto que el acceso al CAE es una característica individual, fue también integrado al modelo en dos de las tres estimaciones como parte del efecto característica, de modo que es posible identificar el efecto parámetro particularmente con el efecto de la imagen institucional. A partir de estos antecedentes es posible establecer dos principales hipótesis:

Hipótesis 1: Se espera que para la comparación entre el grupo 1 (2010-2012) y el grupo 2 (2013) prime el efecto parámetro (imagen institucional) por sobre el efecto característica (características individuales). Esto en la medida que, por una parte, no hay motivos para pensar que las características de los estudiantes del grupo 2 serían distintas a las del grupo 1, pues la pérdida de la acreditación es posterior al ingreso de los estudiantes. Por otra parte, el cambio en la condición de acreditación de la universidad no sólo es en sí mismo un motivo* para un empeoramiento en la imagen de la institución y, por lo tanto, de la retención, sino que supone un cambio en las condiciones en base a las que se generaron las expectativas de los estudiantes (Tinto, 1975), aumentando las posibilidades de deserción.

Hipótesis 2: Aunque se espera observar un efecto parámetro importante -por el empeoramiento en la imagen institucional que conlleva la pérdida de la acreditación-, se espera que en la comparación entre los grupos 1 (2010-2012) y 3 (2014) predomine el efecto de las variables explicativas. Esto debido a que los estudiantes ingresan a la UDLA sabiendo que no está acreditada, por lo que no se observaría el efecto del incumplimiento de las expectativas de los estudiantes. Asimismo, se espera que el cambio en la composición de los estudiantes para 2014 se traduzca en un aumento del efecto característica.

\section{RESULTADOS Y DISCUSIÓN}

La Tabla 1 contiene la estadística descriptiva de la muestra que se empleó para la estimación. Ésta permite identificar los cambios en las variables independientes u observables que afectan la tasa de retención. Estas variables dan cuenta del cambio en la composición de los estudiantes que ingresaron a la UDLA entre 2010 y 2014, en el período correspondiente a cada uno de los grupos. Cada variable independiente tiene un parámetro de sensibilidad, que pondera su efecto final sobre la retención, pudiendo este variar durante el tiempo (como se refleja en nuestra aplicación del modelo de Yun por los subíndices $t$ y $t^{*}$ del parámetro $\beta$ ), cuyo cambio es el "efecto parámetro" mencionado en la sección metodológica. En la Tabla 1, a NEM máximo es 7. b PSU rendida desde el año 2009. No se cuenta con la información para años anteriores. ( $\left.{ }^{\star \star *}\right)$ 
Significancia estadística al 5\% de confianza.

Tabla 1. Estadística descriptiva de la muestra

\begin{tabular}{|c|c|c|c|c|c|}
\hline \multirow[b]{2}{*}{ Variable dependiente } & \multirow{2}{*}{$\begin{array}{c}\text { Grupo } 1 \\
\text { Cohorte } \\
2010-2012\end{array}$} & \multirow{2}{*}{$\begin{array}{c}\text { Grupo } 2 \\
\text { Cohorte } 2013\end{array}$} & \multirow{2}{*}{$\begin{array}{c}\text { Grupo } 3 \\
\text { Cohorte } 2014\end{array}$} & \multicolumn{2}{|c|}{ Brechas } \\
\hline & & & & G1-G2 & G1-G3 \\
\hline Tasa de retención de primer año & $78,07 \%$ & $65,97 \%$ & $64,83 \%$ & $-12,10 \%$ & $-13,25 \%$ \\
\hline$N^{\circ}$ de casos & 24.018 & 10.492 & 5.774 & 2.486 & -2.232 \\
\hline \multirow{2}{*}{ Variables explicativas } & Grupo 1 & Grupo 2 & Grupo 3 & \multicolumn{2}{|c|}{ Brechas } \\
\hline & $\begin{array}{c}\text { Cohorte } \\
2010-2012\end{array}$ & Cohorte 2013 & Cohorte 2014 & G1-G2 & G1-G3 \\
\hline \multicolumn{6}{|l|}{ Nivel educacional previo } \\
\hline NEM promedio ${ }^{a}$ & 5,53 & 5,50 & 5,46 & $-0,28$ & $-0,63$ \\
\hline PSU promedio & 477,66 & 463,26 & 440,63 & $-14,41$ & $-37,03^{\star \star \star}$ \\
\hline$\%$ alumnos con PSU rendida ${ }^{b}$ & $54,81 \%$ & $58,76 \%$ & $48,30 \%$ & $3,95 \%$ & $-6,50 \%$ \\
\hline \multicolumn{6}{|l|}{ Variables demográficas } \\
\hline Edad promedio & 23,94 & 24,05 & 25,99 & 0,11 & 2,05 \\
\hline Mujeres (\%) & $55,80 \%$ & $55,24 \%$ & $54,26 \%$ & $-0,56 \%$ & $-1,54 \%$ \\
\hline \multicolumn{6}{|l|}{ Colegio de origen } \\
\hline Municipal (\%) & $32,91 \%$ & $33,76 \%$ & $34,88 \%$ & $0,85 \%$ & $1,97 \%$ \\
\hline Subvencionado (\%) & $43,16 \%$ & $45,47 \%$ & $43,35 \%$ & $2,31 \%$ & $0,19 \%$ \\
\hline Particular (\%) & $5,67 \%$ & $4,99 \%$ & $6,22 \%$ & $-0,67 \%$ & $0,55 \%$ \\
\hline Sin información (\%) & $18,26 \%$ & $15,77 \%$ & $15,55 \%$ & $-2,49 \%$ & $-2,71 \%$ \\
\hline \multicolumn{6}{|l|}{ Régimen } \\
\hline Diurno (\%) & $61,36 \%$ & $58,93 \%$ & $48,35 \%$ & $-2,43 \%$ & $-13,01 \%^{* * *}$ \\
\hline Vespertino (\%) & $12,57 \%$ & $16,90 \%$ & $20,06 \%$ & $4,32 \%$ & $7,48 \%$ *** \\
\hline Executive (\%) & $26,06 \%$ & $24,17 \%$ & $31,59 \%$ & $-1,89 \%$ & $5,53 \%$ *** \\
\hline \multicolumn{6}{|l|}{ Nivel de carrera } \\
\hline Profesional & $84,09 \%$ & $76,48 \%$ & $79,53 \%$ & $-7,61 \%$ & $-4,56 \%$ \\
\hline Técnico & $15,91 \%$ & $23,52 \%$ & $20,47 \%$ & $7,61 \%$ & $4,56 \%$ \\
\hline \multicolumn{6}{|l|}{ Facultad } \\
\hline Ciencias Sociales (\%) & $7,06 \%$ & $4,98 \%$ & $7,15 \%$ & $-2,08 \%$ & $0,09 \%$ \\
\hline Arquitectura, Diseño y Construcción (\%) & $4,39 \%$ & $4,05 \%$ & $4,19 \%$ & $-0,34 \%$ & $-0,20 \%$ \\
\hline Ciencias de la Salud (\%) & $24,02 \%$ & $23,80 \%$ & $18,93 \%$ & $-0,22 \%$ & $-5,09 \% * * *$ \\
\hline Comunicaciones y Artes (\%) & $4,69 \%$ & $4,16 \%$ & $4,21 \%$ & $-0,53 \%$ & $-0,48 \%$ \\
\hline Derecho (\%) & $5,05 \%$ & $4,09 \%$ & $4,76 \%$ & $-0,96 \%$ & $-0,29 \%$ \\
\hline Educación & $18,89 \%$ & $17,26 \%$ & $18,91 \%$ & $-1,63 \%$ & $0,02 \%$ \\
\hline Ingeniería y Negocios (\%) & $31,05 \%$ & $36,38 \%$ & $36,18 \%$ & $5,33 \% * * *$ & $5,13 \% \%^{* * *}$ \\
\hline Medicina Veterinaria y Agronomía (\%) & $2,85 \%$ & $2,75 \%$ & $3,27 \%$ & $-0,10 \%$ & $0,42 \%$ \\
\hline Instituto del Deporte (\%) & $2,00 \%$ & $2,54 \%$ & $2,39 \%$ & $0,54 \%$ & $0,39 \%$ \\
\hline \multicolumn{6}{|l|}{ Tipo de financiamiento del estudiante } \\
\hline Con CAE al primer año & $31,40 \%$ & $25,22 \%$ & $0,00 \%$ & $-6,18 \%$ & $-31,4 \% * * *$ \\
\hline Se gana el CAE al año siguiente & $16,66 \%$ & $0,00 \%$ & $0,00 \%$ & $-16,66 \%$ *** & $-16,66 \%$ *** \\
\hline Se gana el CAE al año subsiguiente & $2,56 \%$ & $0,00 \%$ & $0,00 \%$ & $-2,56 \%$ *** & $-2,56 \% * * *$ \\
\hline
\end{tabular}


Como se observa en la Tabla 1, la UDLA, estando acreditada, presenta una tasa de retención de un 78,07\% entre 2010 y 2012 (grupo 1), bajando a un 65,97\% para la cohorte 2013 (grupo 2) - que cursaba primer año cuando la UDLA pierde su acreditación. La tasa de retención baja a 64,83\% para la cohorte 2014 (grupo 3), que entra sabiendo que la universidad no está acreditada. Se observa además que, una vez perdida la acreditación, empeoran los indicadores académicos: hacia 2014 baja el promedio del NEM, cae el promedio PSU y cae el porcentaje de estudiantes que dan la PSU. A su vez, se registra un aumento de la edad promedio, sobre todo en el caso del grupo 3 (2014). La cantidad de estudiantes matriculados en los regímenes vespertino y executive aumentan en un 7,5\% y 5,5\%, respectivamente en 2014 (grupo 3); mientras que el porcentaje de estudiantes en régimen diurno cae un $13,0 \%$. Se observa también un aumento de $4,6 \%$ en la matrícula de las carreras técnicas (grupo 3), y una baja de 5,1\% en la matrícula de la Facultad de Ciencias, ligado a un aumento en igual porcentaje de la matrícula de la Facultad de Ingeniería y Negocios.

Sobre el financiamiento mediante el CAE, se confirma una caída en el porcentaje de alumnos con el beneficio. Mientras que un 31,4\% de los estudiantes del grupo 1 (2010-2012) y un 25,2\% en el grupo 2 (2013) obtienen el beneficio al primer año de sus estudios, la cohorte 2014 (grupo 3) no cuenta con acceso al CAE por la pérdida de la acreditación. Un 16,7\% del grupo 1 (2010-2012) accedió al CAE en el segundo año de sus estudios si no postuló el primer año y un $2,6 \%$ en su tercer año si no lo obtuvo en los primeros dos años. Los estudiantes del grupo 2 (2013) están inhabilitados de postular al CAE desde su segundo año si no lo obtuvieron antes por la pérdida de acreditación, que es también el caso para estudiantes de la cohorte 2012 que postulan en su tercer año.

La Tabla 2 contiene los resultados de la descomposición utilizando tres especificaciones distintas. En primer lugar, se hizo la estimación usando solo las variables relativas al perfil de los alumnos (sexo, edad, colegio de origen, etc.) y a las preferencias educativas (régimen de estudio, campus, facultad). Luego se realizó otra estimación incluyendo si los alumnos estudiaron con CAE el primer año. Finalmente, se incorporó a la estimación a los estudiantes que lograron adjudicarse el CAE en años posteriores. El objetivo de realizar estas tres estimaciones diferentes es para ver en primer lugar el efecto separado del CAE si se obtiene en el primer año, al comparar las primeras dos especificaciones. La última especificación sirve para ver la heterogeneidad en la obtención del CAE en diferentes años de la carrera, comparando sus resultados con la segunda especificación.

Tabla 2. Resultados de la descomposición de Yun en la tasa de retención al primer año. En la tabla, Nota: ( ${ }^{* * *}$ ) Significancia estadística al $5 \%$ de confianza.

\begin{tabular}{|c|c|c|c|c|}
\hline \multirow{2}{*}{$\begin{array}{l}\text { Tipo de variable } \\
\text { explicativa }\end{array}$} & \multicolumn{2}{|l|}{ G1-G2 } & \multicolumn{2}{|l|}{ G1-G3 } \\
\hline & $\begin{array}{c}\text { Cambio en tasa de retención } \\
\text { de 1er año }\end{array}$ & Porcentaje & $\begin{array}{c}\text { Cambio en tasa de retención } \\
\text { de 1er año }\end{array}$ & Porcentaje \\
\hline \multicolumn{5}{|c|}{$\begin{array}{l}\text { 1. Con variables de perfil y } \\
\text { composición }\end{array}$} \\
\hline Efecto característica & $-0,9 \%$ & $7,9 \%$ & $-1,4 \%$ & $10,9 \%$ \\
\hline Efecto parámetro & $-11,1 \%$ & $92,1 \%$ *** & $-11,8 \%$ & $89,1 \%$ *** \\
\hline Brecha bruta & $-12,1 \%$ & $100,0 \%$ & $-13,3 \%$ & $100,0 \%$ \\
\hline \multicolumn{5}{|l|}{$\begin{array}{l}\text { 2. Incluyendo CAE el } \\
\text { primer año }\end{array}$} \\
\hline Efecto característica & $-0,8 \%$ & $6,4 \%$ & $-2,6 \%$ & $19,4 \% * * *$ \\
\hline Efecto parámetro & $-11,3 \%$ & $93,6 \%$ *** & $-10,7 \%$ & $80,6 \%$ *** \\
\hline Brecha bruta & $-12,1 \%$ & $100,0 \%$ & $-13,3 \%$ & $100,0 \%$ \\
\hline \multicolumn{5}{|c|}{$\begin{array}{l}\text { 3. Incluyendo CAE años } \\
\text { posteriores }\end{array}$} \\
\hline Efecto característica & $-7,7 \%$ & $63,5 \%$ *** & $-11,7 \%$ & $87,8 \%$ *** \\
\hline Efecto parámetro & $-4,4 \%$ & $36,5 \%$ *** & $-1,6 \%$ & $12,2 \%$ \\
\hline Brecha bruta & $-12,1 \%$ & $100,0 \%$ & $-13,3 \%$ & $100,0 \%$ \\
\hline
\end{tabular}

Al controlar solo por las variables de perfil y composición de la matrícula (primera estimación), el efecto característica solo explica un 7,9\% de la brecha entre los grupos 1 (2010-2012) y 2 (2013) y un 10,9\% de la brecha entre los grupos 1 (2010-2012) y 3 (2014). Es decir que, como consecuencia de cambios en el perfil 
académico y sociodemográfico, y en la composición de la matrícula, la caída fue de alrededor de 0,79 puntos para el primer caso y de 1,09 puntos porcentuales para el segundo. En ambas comparaciones, el segmento de la brecha entre las tasas de retención explicada por el efecto parámetro superó los 11 puntos porcentuales de un total de 12,1 en la comparación entre los grupos 1 y 2 y de un total de 13,3 en la comparación entre los grupos 1 y 3 . Es decir, el efecto parámetro explica, en la primera estimación, un 92,1\% de la brecha de la tasa de retención entre los grupos 1 y 2 y un $89,1 \%$ entre los grupos 1 y 3 . Considerando los antecedentes desarrollados en las secciones anteriores, es posible afirmar que las variables individuales de los estudiantes explican un $7,9 \%$ y $10,9 \%$ de la brecha para la primera y segunda comparación, respectivamente. Por otra parte, al no incorporar la variable "CAE", esta primera estimación permite identificar el efecto "neto" de la pérdida de acreditación. Este efecto incluiría el efecto que la pérdida de acreditación tiene mediante la pérdida de acceso al CAE y mediante el efecto subjetivo, relativo a un cambio en la imagen institucional. Así, la pérdida de la acreditación explicaría, respectivamente, un $92,1 \%$ y un $89,1 \%$ de la brecha.

La segunda estimación, que incluye el financiamiento mediante CAE en primer año entre las variables que dan lugar al efecto característica, no presenta mayores cambios para la cohorte 2013 (grupo 2), pero sí para la cohorte 2014 (grupo 3). En el caso de la comparación entre los grupos 1 (2010-2012) y 2 (2013), se observa una reducción del efecto característica con la incorporación del acceso a CAE en primer año, de 7,9 (primera estimación) a 6,4 (segunda estimación) puntos porcentuales. Esto se explicaría porque el grupo 2 (2013) aún tiene acceso al CAE, contribuyendo a la retención y, por lo tanto, disminuyendo el efecto característica. Por otra parte, el aumento del efecto característica en la comparación entre el grupo 1 (2010-2012) y el grupo 3 (2014) se explicaría porque los estudiantes que ingresan en 2014 no pudieron optar al CAE por la pérdida de acreditación, aumentando la influencia del CAE en la caída en la retención. El aumento del efecto característica estaría también explicado por los cambios en el perfil de los estudiantes que se observan en el grupo 3 (2014). De este modo, el efecto característica explica 2,6 puntos porcentuales de los 13,3 que componen la brecha entre el grupo 1 y el grupo 3. En estos términos, el porcentaje la brecha entre los grupos 1 y 3 que se explica por el efecto característica corresponde un 19,4\%. En esta estimación, el efecto parámetro explicaría un 93,6\% de la brecha entre el grupo 1 (2010-2012) y el grupo 2 (2014), que se reduce a un 80,6\% en el caso de la comparación entre el grupo 1 y el grupo 3 (2014).

La tercera estimación incorpora todas las tres variables relacionadas con el acceso al CAE: quienes postulan en primer año, al año siguiente y al año subsiguiente. Esto permite mover completamente el componente CAE desde efecto parámetro al efecto característica, separando los dos principales efectos de la pérdida de acreditación: el acceso al CAE y el cambio en la imagen institucional. Así, es posible responder a la pregunta sobre cuánto de la caída en la tasa de retención puede atribuirse a cada uno de estos efectos. En esta estimación, las variables observables explican la brecha entre los grupos 1 (2010-2012) y 2 (2013) en un $63,5 \%$ y entre los grupos 1 y 3 (2014) en un $87,8 \%$. De este modo, el efecto característica tiene un impacto mucho mayor en la tercera estimación que en las dos anteriores. En particular respecto de la segunda estimación, este aumento en el efecto característica estaría dado por la incorporación de las variables ligadas a la postulación al CAE en segundo y tercer año. Esto demostraría que el impacto de la pérdida de acreditación sobre la tasa de retención estaría dado principalmente por la pérdida del acceso al financiamiento mediante $\mathrm{CAE}$. Igualmente, demostraría que el CAE es una variable que tiene un efecto de mediano plazo sobre la tasa de retención.

A su vez, si entendemos el efecto parámetro como el efecto de un empeoramiento en la imagen institucional que resulta de la pérdida de acreditación, es posible afirmar que tal empeoramiento explica un $36,5 \%$ de la disminución en la tasa de retención entre los grupos 1 y 2 , y un a 12,2\% de la disminución entre los grupos 1 y 3. Sobre las diferencias entre la comparación G1-G2 y G1-G3, aunque son mayores en la tercera estimación que en estimaciones anteriores, es posible explicarlas a partir de los mismos fenómenos. En el caso del efecto característica el aumento de $63,5 \%$ a $87,8 \%$ se relaciona, en parte, con el cambio en los perfiles de los estudiantes entre 2013 y 2014 que resulta de la pérdida de acreditación. También se debería a la imposibilidad de acceder al CAE en 2014, variable que en esta estimación forma parte del efecto característica. En el caso del efecto parámetro, es esperable que tenga un mayor impacto en la comparación entre los grupos 1 (20102012) y 2 (2013), pues, como se señaló anteriormente, además del efecto de un empeoramiento de la imagen institucional como resultado de la pérdida de acreditación, hay un cambio en las condiciones sobre las que los estudiantes construyeron sus expectativas.

\section{CONCLUSIONES}

El presente trabajo examinó los efectos de la pérdida de acreditación (2013) en la tasa de retención de primer año en la UDLA. Los resultados obtenidos muestran que: 1) Una vez controladas las variables relativas a características individuales habitualmente asociadas con la retención institucional, la pérdida de acreditación institucional explica alrededor del 90\% de la caída en la retención tanto en 2013 como en 2014. 2) El aumento del efecto característica ligado a la incorporación del efecto al largo plazo del CAE permite afirmar que la 
mayor parte del efecto de la pérdida de la acreditación sobre la tasa de retención se explica por la pérdida de acceso al financiamiento mediante CAE tanto en 2013 como en 2014. 3) El empeoramiento de la imagen institucional de la UDLA que resulta de la pérdida de acreditación tiene un efecto relevante sobre la tasa de retención, explicando entre un 12,2\% (2014) y un 36,5\% (2013) de su caída. 4) Existen diferencias en la composición del efecto de la acreditación sobre la retención entre 2013 y 2014: mientras que el efecto de la pérdida de acceso al CAE es particularmente relevante para 2014, el efecto del empeoramiento de la imagen institucional en 2013 es el triple del que se observa en 2014. Esto respondería al cambio en las condiciones institucionales sobre las que los estudiantes construyeron sus expectativas, dando cuenta de la percepción de la institución como un efecto fundamentalmente de corto plazo.

\section{REFERENCIAS}

Araneda-Guirriman, C.A., Rodríguez-Ponce, E.R., y Pedraja-Rejas, L.M., Relación entre el financiamiento fiscal, la calidad del cuerpo académico y la retención de estudiantes universitarios en Chile, http://dx.doi.org/10.4067/S071850062013000600006, Formación Universitaria, 6(6), 55-64 (2013)

Attinasi Jr., L.C., Getting in: mexican americans' perceptions of university attendance and the implications for freshman year persistence, https://doi.org/10.2307/1982250, The Journal of Higher Education, 60(3), 247-277 (1989)

Azoury, N.M., Daou, L.E., y El Khoury, C.M., University image and its relationship to student satisfaction - case of the middle eastern private business schools, https://doi.org/10.1016/j.ism.2014.07.001, International Strategic Management Review, 2(1), 1-8 (2014)

Barra, A.M., La importancia de la productividad científica en la acreditación institucional de universidades, http://dx.doi.org/10.4067/S0718-50062019000300101, Formación Universitaria, 12(3), 101-110 (2019)

Beerli Palacio, A., Díaz Meneses, G., y Pérez Pérez, P.J., The configuration of the university image and its relationship with the satisfaction of students, https://doi.org/10.1108/09578230210440311, Journal of Educational Administration, 40(5), 486-505 (2002)

Blinder, A.S., Wage discrimination: reduced form and structural estimates, https://doi.org/10.2307/144855, The Journal of Human Resources, 8(4), 436-455 (1973)

Braxton, J.M., Milem, J.F., y Sullivan, A.S., The influence of active learning on the college student departure process: toward a revision of Tinto's theory, https://doi.org/10.2307/2649260, The Journal of Higher Education, 71(5), 569-590 (2000)

Braxton, J.M., Shaw-Sullivan, A.V., y Johnson, R.M., Appraising Tinto's theory of college student departure, Higher education handbook of theory and research, Agathon Press, 12, 107-164, New York, USA (1997)

Eccles, J., Adler, T.F., y otros cinco autores, Expectancies, values, and academic behaviors, Achievement and achievement motives: psychological and sociological approaches, W. H. Freeman and Company, 75-146, San Francisco, USA (1983)

Espinoza, O., Privatización de la educación superior en Chile: consecuencias y lecciones aprendidas, https://doi.org/10.5585/eccos.n44.8070, EccoS-Revista Científica, (44), 175-202 (2017)

Ethington, C.A., A psychological model of student persistence, https://doi.org/10.1007/bf00992313, Research in Higher Education, 31(3), 279-293 (1990)

Fishbein, M., y Ajzen, I., Belief, attitude, intention and behavior: an introduction to theory and research, Addison-Wesley Publishing Company, Reading, USA (1975)

Himmel, E., Modelos de análisis de la deserción estudiantil en la educación superior, https://doi.org/10.31619/caledu.n17.409, Calidad en la Educación, (17), 91-108 (2002)

Huerta-Riveros, P.C., y Gaete-Feres, H.G., Análisis de la dependencia de la acreditación institucional: un estudio comparativo de universidades en Chile, http://dx.doi.org/10.15517/aie.v18i1.31748, Actualidades Investigativas en Educación, 18(1), 345-375 (2018)

Mulyono, H., Hadian, A., Purba, N, y Pramono, R., Effect of service quality toward student satisfaction and loyalty in higher education, https://doi.org/10.13106/jafeb.2020.vol7.no10.929, Journal of Asian Finance, Economics and Business, 7(10), 929-938 (2020)

Kunanusorn, A., y Puttawong, D., The mediating effects of satisfaction on student loyalty to higher education institution, ISSN: 1857-7431, European Scientific Journal, 11(10), 449-463 (2015)

Mineduc, Deserción en la educación superior en Chile, Serie Evidencias, 1(9), Centro de Estudios, Ministerio de Educación, Santiago, Chile (2012)

Mineduc, Ley № 20.129 Establece un sistema nacional de aseguramiento de la calidad de la educación superior, Ministerio de Educación, Santiago, Chile (2006) 
Navarrete, S., Candia, R., y Puchi, R., Factores asociados a la deserción/retención de los estudiantes mapuche de la Universidad de La Frontera e incidencia de los programas de apoyo académico, http://dx.doi.org/10.4067/S071845652013000200003, Calidad en la Educación, (39), 43-80 (2013)

Oaxaca, R., Male-female wage differentials in urban labor markets, https://doi.org/10.2307/2525981, International Economic Review, 14(3), 693-709 (1973)

Rau, T., Rojas, E., y Urzúa, S., Loans for higher education: does the dream come true?, https://doi.org/10.3386/w19138, National Bureau of Economic Research, (w19138) (2013)

Santelices, M.V., Catalán, X., Kruger, D., y Horn, H., Determinants of persistence and the role of financial aid: lessons from Chile, https://doi.org/10.1007/s10734-015-9906-6, Higher Education, 71(3), 323-342 (2016)

SIES, Retención de primer año en educación superior, Programas de pregrado, División de educación superior, Servicio de información de educación superior, Ministerio de Educación, Santiago, Chile (2014a)

SIES, Panorama de la educación superior en Chile 2014, División de educación superior, Servicio de información de educación superior, Ministerio de Educación, Santiago, Chile (2014b)

Spady, W.G., Dropouts from higher education: an interdisciplinary review and synthesis, https://doi.org/10.1007/bf02214313, Interchange, 1(1), 64-85 (1970)

St. John, E.P., Cabrera, A.F., Nora, A., y Asker, E.H., Economic influences on persistence reconsidered: how can finance research inform the reconceptualization of persistence models?, Reworking the student departure puzzle, Vanderbilt University Press, 29-47, Nashville, USA (2000)

Thomas, S., What drives student loyalty in universities: an empirical model from India, https://doi.org/10.5539/ibr.v4n2p183, International Business Research, 4(2), 183-192 (2011)

Tinto, V., Dropout from higher education: a theoretical synthesis of recent research, https://doi.org/10.3102/00346543045001089, Review of Educational Research, 45(1), 89-125 (1975)

UDLA, Informe de autoevaluación institucional, Universidad de Las Américas, Santiago, Chile (2015)

Yun, M.S., Decomposing differences in the first moment, https://doi.org/10.1016/j.econlet.2003.09.008, Economics Letters, 82(2), 275-280 (2004) 
